\title{
Gossipyboma in the Breast: A Rare Case Report
}

\author{
Onder Yeniceri ${ }^{\mathrm{a}}$, Pinar Balci ${ }^{\mathrm{b}}$, Nesat Cullu ${ }^{\mathrm{c}, \mathrm{d}}$, Mehmet Deveer
}

\begin{abstract}
The term "gossipyboma" is used to define surgical sponges left in the body after an operation. As the area where the procedure is made is small and the surgeon is generally in control of the surgical area, this is a rare occurrence in the breast. Although there may be imaging findings which have been generated due to reactions, there are very few diagnostic findings for gossipyboma and some cases can be confusing. The case is presented here of gossipyboma found in the breast of a 65 -year-old patient.
\end{abstract}

Keywords: Breast; Gossipyboma; Mammography; Ultrasonography

\section{Introduction}

The term "gossipyboma" is used to define surgical sponges left in the body after an operation. Due to legal and ethical problems, the real frequency is unknown. As the area where the procedure is made is small and the surgeon is generally in control of the surgical area, this is a rare occurrence in the breast. Although there may be imaging findings which have been generated due to reactions, there are very few diagnostic findings for gossipyboma and some cases can be confusing [1]. The case is presented here of gossipyboma found in the breast of a 65 -year-old patient.

\footnotetext{
Manuscript accepted for publication January 14, 2014

${ }^{\mathrm{a} D}$ Department of Radiology, Yucelen Hospital, Mugla, Turkey

${ }^{\mathrm{b}}$ Department of Radiology, Faculty of Medicine, Dokuz Eylul University, Izmir, Turkey

${ }^{\mathrm{c}}$ Department of Radiology, Faculty of Medicine, Mugla Sitki Kocman University, Mugla, Turkey

${ }^{\mathrm{d}}$ Corresponding author: Nesat Cullu, Central Campus, Department of Radiology, School of Medicine, Mugla Sitki Kocman University, 48000 Mugla, Turkey. Email: nesatcullu77@gmail.com
}

doi: http://dx.doi.org/10.14740/jmc1690e

\section{Case Report}

A 65-year-old female presented with complaints of discharge from the surgical field of the upper inner quadrant (UIQ) of the right breast. There was a history of lumpectomy 2 months previously for a breast tumor (BI-RADS V). One week after the lumpectomy, a serous discharge from the wound site started and continued. The discharge was not flowing strongly and was caused by changing the dressing twice daily. Microbiologic examination of the discharge revealed no reproduction and thus the discharge was thought to be reactive. The patient presented at hospital as her complaints had not been resolved. In the physical examination, there was an incision of approximately $5-6 \mathrm{~mm}$ in the UIQ of the right breast. A serous discharge was observed from a defect of approximately $5 \mathrm{~mm}$ in the mid-section of the incision. On palpation, a mass was felt. In B-mode ultrasonography (USG) a mass was observed, approximately $3 \times 2 \mathrm{~cm}$ in size, with light acoustic shadow, which was hypoechoic and irregular and located vertically (Fig. 1). The mass had led to shrinkage in the surrounding tissues. When the lesion was

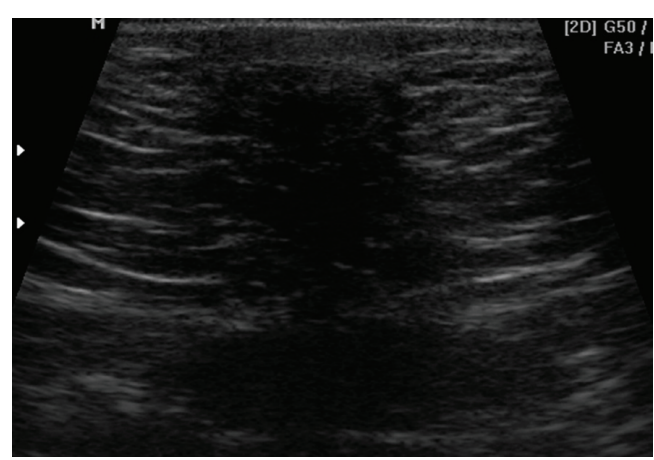

Figure 1. In B-mode ultrasonography (USG) a hypoechoic mass was observed, approximately $3 \times 2 \mathrm{~cm}$ in size, with light acoustic shadow, irregular contours, and located vertically due to shrinking in the surrounding tissues. When the lesion was evaluated only with the USG findings, it had the properties of BI-RADS V appearance. 


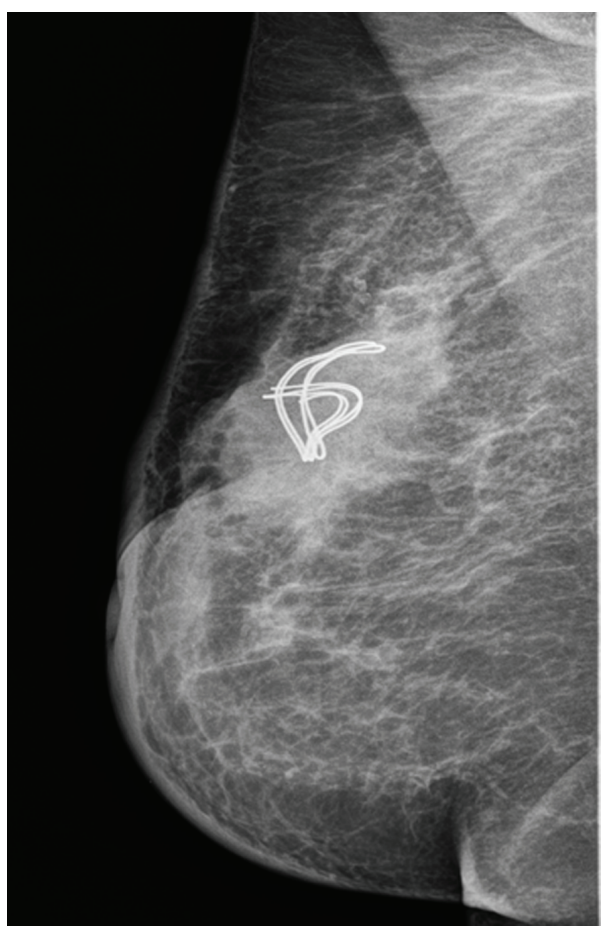

Figure 2. On the MLO radiograph, asymmetric density of equivalent intensity to breast glandular tissue in the surgical localisation of the right breast upper quadrant was observed. Within this area there was a twisted, linear appearance, which was thought to be suture material.

evaluated only with the USG findings, it had the properties of BIRADS V appearance. Mammography (MG) was then applied to the patient. On the medio-lateral oblique (MLO) radiograph, asymmetric density of equivalent intensity to breast glandular tissue in the surgical localization of the right breast upper quadrant was observed (Fig. 2). Within this area there was a twisted, linear appearance, which was thought to be suture material. Shrinkage in the skin in this area, which was thought to be secondary to the operation, accompanied the findings. From all these findings, the patient was admitted for surgery with a preliminary diagnosis of gossipyboma. A surgical sponge containing rolled suture material was removed (Fig. 3).

\section{Discussion}

Gossipyboma is a non-medical term to describe a surgical sponge left in the body after an operation [1]. The true frequency of all cases is unknown because of legal and ethical concerns. It is generally observed after abdominal surgery and may also be seen in the thoracic area [2], the central nervous system [3] and in the extremities [4]. In surface tissues such as the breast, it is extremely rare. Diagnostic difficulties

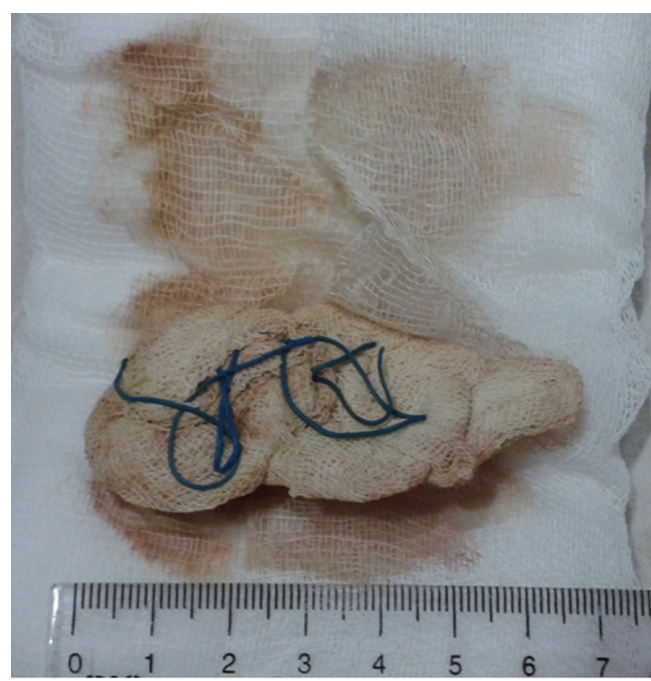

Figure 3. A surgical sponge containing rolled suture material was observed.

are experienced because of confusion of what is seen with tumor, abscess or hematoma.

The clinical findings of gossipyboma show variations depending on location and the reaction created. While it may be determined coincidentally especially in internal abdominal organs, it can sometimes be fatal [1]. Although in surface tissue such as in the breast, findings are generally evident very soon, different clinical findings may be observed from asymptomatic granulomatosis to the appearance of abscessfistula $[5,6]$.

The radiologic appearance of gossipyboma represents the reaction created. While ultrasonography is useful in surface tissues, sensitivity in the determination of lesions in the abdomen, especially between intestinal loops is low compared to computerized tomography (CT). Although the ultrasonographic image shows variations depending on the time it has remained in the body and the reaction which has been created, it is generally non-specific. As in the case presented here, cystic, hypoechoic and complex masses can be seen as an acoustic shadowing showing an irregular mass [7].

The use of sponges containing radio-opaque markers in cases undergoing abdominal surgery in particular, facilitates detection by radiography [4]. In these types of cases mammography is the method with the highest sensitivity in the determination of lesions in the breast. In the case reported here, a radio-opaque marker was determined on mammography which was applied directed towards the diagnosis of gossipyboma. In the light of clinical findings, USG and MG are sufficient in the diagnosis of lesions in the breast. However, there are also cases in literature where diagnosis has been made from magnetic resonance imaging (MRI) and CT $[7,8]$.

In conclusion, even though it is rarely seen, gossipyboma should be considered in the differential diagnosis when 
a mass is determined in the surgical site of cases after operations. If sponges with radio-opaque markers are used, diagnosis can be made easily with mammography. In cases where radio-opaque markers are not observed, contrast CT and MRI may be beneficial.

\section{Grant Support and Other Assistance}

None.

\section{Conflicts of Interest}

The authors declared no conflicts of interest.

\section{References}

1. Manzella A, Filho PB, Albuquerque E, Farias F, Kaercher J. Imaging of gossypibomas: pictorial review. AJR Am J Roentgenol. 2009;193(6 Suppl):S94-101.
2. Sheehan RE, Sheppard MN, Hansell DM. Retained intrathoracic surgical swab: CT appearances. J Thorac Imaging. 2000;15(1):61-64.

3. Ebner F, Tolly E, Tritthart H. Uncommon intraspinal space occupying lesion (foreign-body granuloma) in the lumbosacral region. Neuroradiology. 1985;27(4):354356.

4. Kul S, Gunes G. Gossypiboma of the breast: imaging findings. J Radiol Case Rep. 2010;4(10):21-25.

5. Apter S, Hertz M, Rubinstein ZJ, Zissin R. Gossypiboma in the early post-operative period: a diagnostic problem. Clin Radiol. 1990;42(2):128-129.

6. Lo CP, Hsu CC, Chang TH. Gossypiboma of the leg: MR imaging characteristics. A case report. Korean J Radiol. 2003;4(3):191-193.

7. Kokubo T, Itai Y, Ohtomo K, Yoshikawa K, Iio M, Atomi Y. Retained surgical sponges: CT and US appearance. Radiology. 1987;165(2):415-418.

8. Sugimura H, Tamura S, Kakitsubata Y, Kakitsubata S, Uwada O, Kihara Y, Nagatomo M, et al. Magnetic resonance imaging of retained surgical sponges. Case report. Clin Imaging. 1992;16(4):259-262. 